\title{
Peptide-Phospholipid Cross-Linking Reactions: Identification of Leucine Enkephalin- Alka(e)nal-Glycerophosphatidylcholine Adducts by Tandem Mass Spectrometry
}

\author{
Ana Reis, Pedro Domingues, António J. V. Ferrer-Correia, \\ and M. Rosário M. Domingues \\ Department of Chemistry, University of Aveiro, Aveiro, Portugal
}

\begin{abstract}
The covalent interactions between peptides and lipid oxidation products, with formation of Schiff and Michael adducts, are known to occur during free radical oxidative damage. In this study, leucine-enkephalin-glycerophosphatidylcholine alka(e)nal adducts were analyzed by electrospray tandem mass spectrometry (MS/MS). Upon collision-induced dissociation of the Leucine enkephalin-2-(9-oxo-nonanoyl)-1-palmitoyl-3-glycerophosphatidylcholine, an alkanal Schiff adduct observed at $\mathrm{m} / \mathrm{z}$ 1187.7, the main product ions were attributed to the phosphocholine polar head and loss of the peptide. Also, product ions resulting from characteristic losses of phosphatidylcholines and cleavages of the peptide chain (mainly b-type) were observed. Additional product ions formed by combined peptide and phosphatidylcholine fragmentations were identified. The fragmentation pattern of the leucine enkephalin-alkanal Schiff adduct and the leucine enkephalin-alkenal phosphatidylcholine Schiff and Michael adducts were similar, although the loss of the peptide for the Michael adduct should occur through a distinct mechanism. These fragmentation pathways differ greatly from those described for peptide-lipid Schiff and Michael adducts, in which only peptide chain cleavages are reported, probably due to charge retention in the glycerophosphatidylcholine polar head in peptideglycerophosphatidylcholine adducts. (J Am Soc Mass Spectrom 2006, 17, 657-660) (c) 2006 American Society for Mass Spectrometry
\end{abstract}

$\mathrm{O}$ xidative damage of peptides/proteins has received increasing attention due to the growing evidence of being associated with diabetes, cancer, and several age-related diseases [1]. The damage can be induced by the structural modification of the peptide/protein by reactive oxygen species (ROS) and other radicalar species, or by cross-linking reactions between peptide/protein and the oxidation products of other biomolecules (lipids, phospholipids, and DNA bases) [1]. The peptide-lipid adducts occur by reaction of the primary amine group (1) with the terminal carbonyl group (named as Schiff adduct), or (2) with the double-bond present in unsaturated aldehydes (named as Michael adduct). Currently, the work published on the peptide-lipid covalent interactions has focused on the identification of peptide adducts formed with the 4-hydroxy-nonenal (4-HNE) [2], which is a secondary oxidation product of $\omega-6$ lipids (such as linoleic and

Published online March 6, 2006

Address reprint requests to Dr. M. R. M. Domingues, Department of Chemistry, University of Aveiro, 3810-193 Aveiro, Portugal.E-mail: mrd@dq.ua.pt arachidonic acids) found in membrane phospholipids, in triglycerides, and in low density lipoprotein [3]. The studies published allowed to propose that the lipid interactions with key amino acids in proteins were responsible for major structure alterations, not just by modification of the catalytic site [4], but also by reaction with surface amino acids [2], which ultimately leads to structural (conformational) changes. Tandem mass spectrometry (MS/MS) studies performed on the peptidelipid Schiff and Michael adducts [2] report only product ions formed by peptide cleavages. Considering the formation of peptide/protein-lipid adducts, peptidephospholipid covalent interactions analogous to the ones described with 4-HNE could occur through reaction between peptide and phosphatidylcholinealka(e)nals. To our knowledge, the identification of peptide-phospholipid interactions was not yet investigated by Mass Spectrometry (MS). As part of an ongoing research on the identification of biomolecules radical oxidation products by MS, the purpose of this study is the characterization of leucine enkephalin-phosphatidylcholine alka(e)nal adducts by MS/MS. 


\section{Experimental}

\section{Phospholipid Oxidative Treatment}

The 1-palmitoyl-2-lineloyl-sn-glycero-3-phosphocholine (PLPC) vesicles were prepared from stock solutions of $1 \mathrm{mg} / \mathrm{mL}$ in chloroform and dried under stream of nitrogen, by adding $\mathrm{HCO}_{3} \mathrm{NH}_{4}$ buffer (5 $\mathrm{mM}, \mathrm{pH}$ 7.4) to a final concentration of $50 \mathrm{mM}$. Metal catalyzed oxidation of PLPC vesicles was performed by the Fenton reaction, as described elsewhere [5].

\section{Peptide-Phospholipid Adduct Incubation}

Twenty $\mu \mathrm{L}$ of $1 \mathrm{mg} / \mathrm{mL}$ leucine enkephalin (LeuEnk) (Sigma, Darmstadt, Germany) stock solution in $\mathrm{HCO}_{3} \mathrm{NH}_{4}$ buffer (5 mM, pH 7.4) was allowed to react with $100 \mu \mathrm{L}$ of the extract containing the PLPC oxidation products (PLPCox) and left to incubate at $37^{\circ} \mathrm{C}$ in the dark $(4-6 \mathrm{~h})$ in inert atmosphere, with occasional stirring. The reaction evolution was monitored by ES-MS.

\section{Electrospray (ES) Mass Spectrometry}

ES mass spectra and tandem mass spectra were acquired in a Q-TOF 2 instrument (Mass Lynx 4.0, Micromass, Manchester, UK) using MassLynx 4.0 software. The peptide-phospholipid adduct analysis was done after diluting $5 \mu \mathrm{L}$ of the sample in $200 \mu \mathrm{L}$ of $\mathrm{MeOH}$. The flow rate was $10 \mu \mathrm{L} / \mathrm{min}$, needle voltage was set at $3 \mathrm{kV}$, cone voltage at $35 \mathrm{~V}$, and ion source at $80^{\circ} \mathrm{C}$. Product-ion spectra (MS/MS) were obtained using argon as the collision gas (measured pressure in the penning gauge $\sim 6 \times 10^{-6} \mathrm{mBar}$ ) and collision energy of $55 \mathrm{eV}$.

\section{Results and Discussion}

Previous work performed on the identification of PLPC radical oxidation products by MS [5-7], reported the presence of the 1-palmitoyl-2-(9-oxo-nonanoyl)-GPC $\left([\mathrm{MH}]^{+}\right.$at $\left.m / z 650.4\right)$, as the major aldehyde product, among the short-chain products with terminal aldehyde at $s n-2$ acyl residues esterified to the 1-palmitoyl-GPC moiety $[5,7]$. Other aldehydes with $C_{7}$ to $C_{12}$ carbon chain length were also identified and characterized by MS/MS [5] and LC-MS [7], such as the ion at $\mathrm{m} / \mathrm{z} 692.5$ identified as the 1-palmitoyl-2-(8-hydroxy-11-oxo-9undecenoyl)-GPC $[5,7]$. The formation of peptides and GPC alka(e)nals Schiff and Michael adducts was attempted by incubation of LeuEnk with an extract containing GPC alka(e)nals and monitored by ES-MS. The ES mass spectrum obtained (Supplementary Figure 1a which can be found in the electronic version of this article.) was compared with the mass spectrum of the PLPCox extract in the absence of the peptide (Supplementary Figure $1 b$ ). Several ions were observed corresponding to the protonated molecules of the peptide $(\mathrm{m} / \mathrm{z}$ 556.3), the native PLPC $(\mathrm{m} / \mathrm{z} 758.5)$, the PLPC short-chain oxidation products [5], the PLPC long-chain products [9], and also ions observed at $\mathrm{m} / \mathrm{z}$ 1187.7, $1193.8,1205.7,1209.7,1221.8,1225.7,1229.7,1243.7$, and 1247.7 that were assigned to LeuEnk-GPC alka(e)nal adducts (Supplementary Figure 1a). 1 The ion at $\mathrm{m} / \mathrm{z}$ 1187.7 may correspond to the Schiff adduct of the LeuEnk-(1-palmitoyl-2-(9-oxo-nonanoyl)-GPC) (Supplementary Scheme $\mathbf{1}$ which can be found in the electronic version of this article.), formed by reaction of the primary amino group (N-terminal) of LeuEnk with the terminal carbonyl group of the $\mathrm{C}_{9}$ shortchain aldehyde, in a manner similar to what is described for peptide-HNE adducts [1]. The ions at $\mathrm{m} / \mathrm{z} 1229.7$ and 1247.7 may be attributed to the Schiff and Michael adducts, respectively, of LeuEnk-1palmitoyl-2-(8-hydroxy-11-oxo-9-undecenoyl)-GPC $(\mathrm{m} / \mathrm{z}$ 692.5). The ion at $\mathrm{m} / \mathrm{z} 1229.7$ showed a very low relative abundance, but the product-ion spectrum obtained confirmed the proposed attribution. Preliminary work performed by MS on LeuEnk incubated with hexanal and 2-hexenal (data not shown), known as secondary radical peroxidation products of $\omega-6$ fatty acids, showed abundant ions attributed to Schiff adducts (for hexanal and 2-hexenal) and Michael adducts (only for 2-hexenal). The LeuEnk-GPC al$\mathrm{ka}(\mathrm{e})$ nal adducts may also be present as doubly charged ions $[\mathrm{MH}+\mathrm{H}]^{2+}$, however they were not assigned due to their low relative abundance in the mass spectrum.

The ions of the LeuEnk-GPC alka(e)nal adducts at $\mathrm{m} / \mathrm{z} 1187.7,1229.7$, and 1247.7 were studied by tandem mass spectrometry (ES-MS/MS).

\section{MS/MS of Peptide-GPC Alkanal Adducts}

The product-ion spectrum of the $[\mathrm{MH}]^{+}$ion of LeuEnk(1-palmitoyl-2-(9-oxo-nonanoyl)-GPC) adduct at $\mathrm{m} / \mathrm{z}$ 1187.7 (Figure 1a) exhibits abundant product ions at $\mathrm{m} / \mathrm{z}$ 184.1 $\left.\left(\left[\mathrm{H}_{2} \mathrm{PO}_{4}\left(\mathrm{CH}_{2}\right)_{2} \mathrm{~N}\left(\mathrm{CH}_{3}\right)_{3}\right)\right]^{+}\right)$, which is the base peak, product ions at $\mathrm{m} / \mathrm{z} 478.4$ attributed to the dehydration ion of the 1-palmitoyl-2-lyso-GPC, and also at $\mathrm{m} / \mathrm{z} 632.2$ that may be formed by loss of the LeuEnk (555 Da). The elimination of LeuEnk cannot be rationalized by direct cleavage of the imine bond formed between the peptide and the GPC alkanal, however this fragmentation can be rationalized considering an initial nucleophilic attack of the nitrogen on the carbonyl group with formation of a six-membered ring structure (Supplementary Scheme 2a which can be found in the electronic version of this article), which leads to doublebond migration and finally to cleavage of the amine bond by a 1,4 elimination mechanism with loss of $\mathrm{H}_{2} \mathrm{O}$. In the mass range of $\mathrm{m} / \mathrm{z} 780$ to 1180 of this spectrum (Figure $1 \mathrm{~b}$ ), the product ions at $m / z 1128.7(-59 \mathrm{Da})$ and 1004.7 ( $-183 \mathrm{Da})$ can be observed, and correspond to loss of $\mathrm{N}\left(\mathrm{CH}_{3}\right)_{3}$ and $\mathrm{HPO}_{4}\left(\mathrm{CH}_{2}\right)_{2} \mathrm{~N}\left(\mathrm{CH}_{3}\right)_{3}$ from the precursor ion, respectively. These are characteristic losses of GPC $[\mathrm{MH}]^{+}$and $[\mathrm{MNa}]^{+}$ions [8], and of GPC 

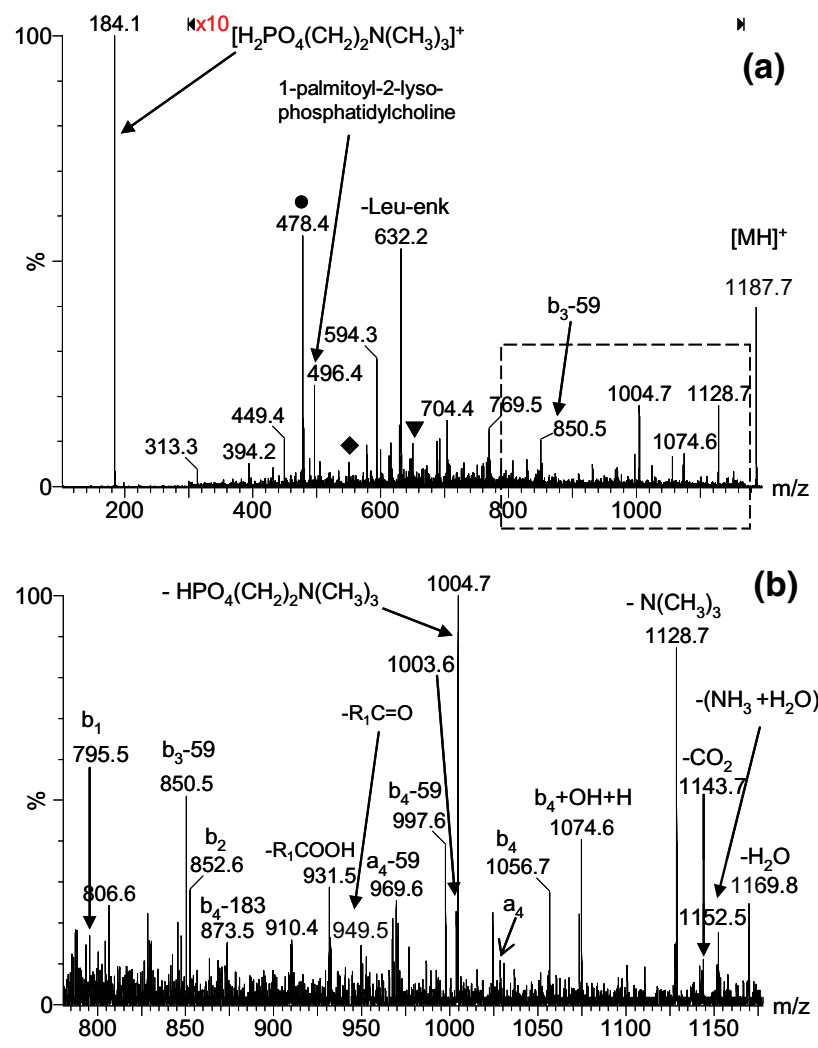

Figure 1. (a) Product-ion spectrum of the $[\mathrm{MH}]^{+}$ion of LeuEnk1-palmitoyl-2-(9-oxo-nonanoyl)-GPC Schiff adduct. (b) Same as (a) showing the mass range of $\mathrm{m} / \mathrm{z} 780$ to 1180 (filled circle, product ion at $\mathrm{m} / \mathrm{z}$ 478.4, filled diamond, product ion at $\mathrm{m} / \mathrm{z} 550.4$, filled inverted triangle, product ion at $\mathrm{m} / \mathrm{z} 650.5$ ).

oxidation products $[5,9]$. On the other hand, the product ions observed at $\mathrm{m} / \mathrm{z} 931.5$ and 949.5 , attributed to loss of palmitic acid as a neutral $\left(-\mathrm{R}_{1} \mathrm{COOH}\right)$ and as ketene $\left(-R_{1}=C=O\right)$ from the precursor ion, respectively, are characteristic fragmentations of the phospholipid $[\mathrm{MH}]^{+}$ions $[5,8,9]$. Overall, the product ions formed by loss of $s n-1$ residue $\left(\mathrm{R}_{1} \mathrm{COOH}\right.$ and $\mathrm{R}_{1}=\mathrm{C}=$ O), and the product ion at $\mathrm{m} / \mathrm{z} 496.4$ attributed to the 1-palmitoyl-2-lyso-GPC (Pathway b in Scheme 1) along with its dehydration product ion at $\mathrm{m} / \mathrm{z} 478.4$ (filled circle in Figure 1a), showed that the peptide was linked to the $s n-2$ acyl residue. The higher relative abundance observed for the 1-palmitoyl-2-lyso-GPC $(\mathrm{m} / \mathrm{z}$ 496.4), resulting from loss of peptide- $\mathrm{R}_{2}=\mathrm{C}=\mathrm{O}$, when compared to the product resulting from loss of $R_{1}=C$ $=\mathrm{O}(\mathrm{m} / \mathrm{z}$ 949.5), observed in Figure $1 \mathrm{~b}$, was earlier described [8], thus allowing identification of the $s n-1$ fatty acid residue. The product ions at $\mathrm{m} / \mathrm{z} 1152.5$ $\left(-\mathrm{NH}_{3}\right.$ and $\left.\mathrm{H}_{2} \mathrm{O}\right), 1143.7\left(-\mathrm{CO}_{2}\right), 1074.6\left(\mathrm{~b}_{4}+\mathrm{OH}\right)$, $1056.7\left(b_{4}\right), 1028.6\left(a_{4}\right), 852.6\left(b_{2}\right)$, and $795.5\left(b_{1}\right)$ observed in Figure 1b, were identified as peptide cleavages corroborating the presence of the LeuEnk linked to the alkanal moiety. The predominance of b-type peptide cleavages is common to product ion spectra obtained with Q-TOF instruments [10], which contrasts with the predominance of y-type product ions in high- energy CID spectra of peptide $[\mathrm{M}+\mathrm{H}]^{+}$ions [11]. Minor product ions observed at $\mathrm{m} / \mathrm{z} 806.6$ (Figure $1 \mathrm{~b}$ ) and 650.5 (filled inverted triangle in Figure 1a) may be attributed to cleavage of the $\beta$-bond of the esterified carboxylic group in the $s n-1$ and $s n-2$ residues, respectively. These fragmentations occur probably by heterolytic cleavage through a McLafferty-like mechanism, and were previously described in tandem mass spectra of oxo fatty acids [12] and of radical peroxidation products of diacyl-GPC [5]. Also, the product ions at $\mathrm{m} / \mathrm{z} 1003.6$ and 550.4 (filled diamond in Figure 1a) result from cleavage of the $\gamma$-bond (Pathway a in Scheme 1), relative to the carboxylic group, occurring at the $s n-1$ and $s n-2$ residues, respectively, possibly through the 1,4 hydrogen elimination mechanism. Additionally, product ions formed by loss of $\mathrm{N}\left(\mathrm{CH}_{3}\right)_{3}$ combined with peptide cleavages were observed at $m / z 573.4$ (loss of LeuEnk), $708.5\left(\mathrm{a}_{1}\right), 765.5$ $\left(\mathrm{a}_{2}\right), 850.5\left(\mathrm{~b}_{3}\right), 969.6\left(\mathrm{a}_{4}\right), 997.5\left(\mathrm{~b}_{4}\right)$, and $1015.6\left(\mathrm{~b}_{4}+\mathrm{OH}\right)$, as exemplified in Scheme 1; and product ions formed by loss of $\mathrm{HPO}_{4}\left(\mathrm{CH}_{2}\right)_{2} \mathrm{~N}\left(\mathrm{CH}_{3}\right)_{3}$ and peptide cleavages at $\mathrm{m} / \mathrm{z}$ $726.5\left(b_{3}\right), 873.5\left(b_{4}\right)$ and 449.4 (loss of LeuEnk) (Scheme 1 ). The loss of $\mathrm{R}_{1}=\mathrm{C}=\mathrm{O}(238 \mathrm{Da})$ combined with loss of LeuEnk $(\mathrm{m} / \mathrm{z}$ 394.2) was also observed.

The fragmentation pathways here described differ greatly from those identified for the lipid-peptide adducts [2], where only peptide chain cleavages are described. The dissimilarity between the fragmentation
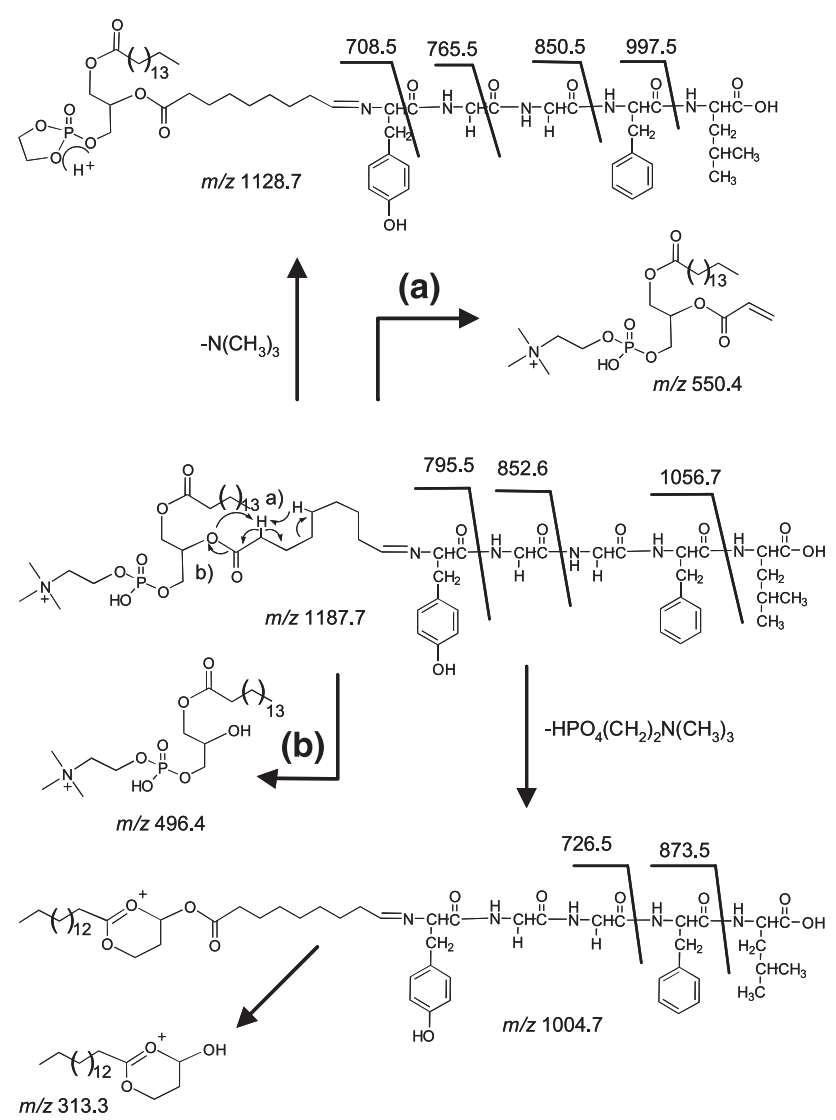

Scheme 1. Proposed fragmentation pathways for the product ions observed in the product ion spectrum of the ion at $\mathrm{m} / \mathrm{z}$ 1187.7. 
pattern of peptide-lipid and peptide-GPC adducts is most probably due to charge retention on the GPC polar head, in contrast with the peptide-lipid adducts where the charge is retained in the peptide moiety. The identification of fragmentation pathways occurring in the peptide and in the phosphatidylcholine moieties gives structural information about the two components of the adducts.

\section{Peptide-Phosphatidylcholine Alkenal Adducts}

The product-ion spectra obtained for the LeuEnk(1-palmitoyl-2-(8-hydroxy-11-oxo-9-undecenoyl)-GPC)) Schiff and Michael adducts (Supplementary Figure 2 which can be found in the electronic version) exhibited similar fragmentation patterns, with the product ion at $\mathrm{m} / \mathrm{z} 184.1$ (base peak) and the product ions formed by loss of $\mathrm{N}\left(\mathrm{CH}_{3}\right)_{3}$ and $\mathrm{HPO}_{4}\left(\mathrm{CH}_{2}\right)_{2} \mathrm{~N}\left(\mathrm{CH}_{3}\right)_{3}$, loss of LeuEnk and loss of $\mathrm{R}_{1} \mathrm{COOH}$ from the precursor ion, as well as the product ions that can be assigned to lysoGPC $(m / z 478.4$ and 496.4). However, the elimination of LeuEnk from the precursor ion for the Michael adduct cannot occur by a mechanism similar to the one proposed for the Schiff adduct, but can be rationalized through a direct 1,2 elimination mechanism (Supplementary Scheme $\mathbf{2 b}$ ). The product ions formed through combined loss of LeuEnk with $\mathrm{N}\left(\mathrm{CH}_{3}\right)_{3}$ and $\mathrm{HPO}_{4}\left(\mathrm{CH}_{2}\right)_{2} \mathrm{~N}\left(\mathrm{CH}_{3}\right)_{3}$ were observed for both peptideGPC adducts, while b-type peptide cleavages were observed with low relative abundance.

\section{Conclusions}

Structural characterization of peptide-GPC alka(e)nal Schiff and Michael adducts by MS/MS showed product ions that resulted from characteristic fragmentations of GPC and of peptides. These differ greatly from the ones described for peptide-lipid adducts, where only peptide cleavages are described. These findings reveal another aspect of cross-linking reactions that may take place in membrane proteins during free radical oxidative damage.

\section{Acknowledgments}

The authors acknowledge the PhD grant to AR (SFRH/BD/ 10358/2002) provided by Fundação para a Ciência e Tecnologia (FCT, Portugal) and Fundo Social Europeu (FSE).

\section{References}

1. Berlett, B. S.; Stadtman, E. R. Protein Oxidation in Aging, Disease, and Oxidative Stress. J. Biol. Chem. 1997, 272, 20313-20316.

2. Carini, M.; Aldini, G.; Facino, R. M. Mass Spectrometry for Detection of 4-Hydroxy-Trans-2-Nonenal (HNE) Adducts with Peptides and Proteins. Mass Spectrom. Rev. 2004, 23, 281-305.

3. Spiteller G. Linoleic Acid Peroxidation-The Dominant Lipid Peroxidation Process in Low Density Lipoprotein and Its Relationship to Chronic Diseases. Chem. Phys. Lipids 1998, 95, 105-162.

4. Ishii, T.; Emi, T.; Shigenori, K.; Nakayama, T.; Uchida, K. Molecular Basis of Enzyme Inactivation by an Endogenous Electrophile 4Hydroxy-2-Nonenal: Identification of Modification Sites in Glyceraldehyde-3-Phosphate Dehydrogenase. Biochem. 2003, 42, 3474-3480.

5. Reis, A.; Domingues, P.; Ferrer-Correia, A. J. V.; Domingues, M. R. M. Fragmentation Study of Short-Chain Products Derived from Oxidation of Diacyl-Phosphatidylcholines by Electrospray Tandem Mass Spectrometry: Identification of Novel Short-Chain Products. Rapid Commun. Mass Spectrom. 2004, 18, 2849-2858.

6. Itabe, H.; Yamamoto, H.; Suzuki, M.; Kawai, Y.; Nakagwa, Y.; Suzuki, A.; Imanaka, T.; Takano, T. Oxidized Phosphatidylcholines that Modify Proteins: Analysis by Monoclonal Antibody Against Oxidized Low Density Lipoprotein. J. Biol. Chem. 1996, 271, 33208-33217.

7. Reis, A.; Domingues, M. R. M.; Amado, F. M. L.; Ferrer-Correia, A. J. V.; Domingues, P. Separation of Peroxidation Products of DiacylPhosphatidylcholines by Reverse-Phase Liquid Chromatography-Mass Spectrometry. Biomed. Chromatogr. 2005, 19, 129-137.

8. Hsu, F.-F.; Turk, J. Electrospray Ionization/Tandem Quadrupole Mass Spectrometric Studies on Phosphatidylcholines: The Fragmentation Process. J. Am. Soc. Mass Spectrom. 2003, 14, 352-363.

9. Reis, A.; Domingues, P.; Ferrer-Correia, A. J. V.; Domingues, M. R. M. Tandem Mass Spectrometry of Intact Oxidation Products of DiacylPhosphatidylcholines: Evidence for the Occurrence of the Oxidation of the Phosphocholine Head and Differentiation of Isomers. J. Mass Spectrom. 2004, 39, 1513-1522.

10. Qin, X.-Z.; Yuan, Y. Electrospray Ionization/Collision-Induced Dissociation of Protonated Substance P Ions-Effect of Charge on the Fragmentation Pattern. Int. J. Mass Spectrom. 2004, 237, 123-133.

11. Paizs, B.; Suhai, S. Fragmentation Pathways of Protonated Peptides. Mass Spectrom. Rev. 2005, 24, 508-548.

12. Cheng, C.; Gross, M. L. Fragmentation Mechanisms of Oxo-Fatty Acids via High-Energy Collisional Activation. J. Am. Soc. Mass Spectrom. 1998, 9, 620-627. 